medRxiv preprint doi: https://doi.org/10.1101/2021.11.10.21266188; this version posted November 11, 2021. The copyright holder for this preprint (which was not certified by peer review) is the author/funder, who has granted medRxiv a license to display the preprint in perpetuity.

It is made available under a CC-BY-NC-ND 4.0 International license .

\title{
A study of the benefits of vaccine mandates and vaccine passports for SARS-CoV-2
}

\author{
Aaron Prosser, MD MSc (corresponding author) \\ Resident, Department of Psychiatry and Behavioural Neurosciences \\ McMaster University \\ aaron.prosser@medportal.ca

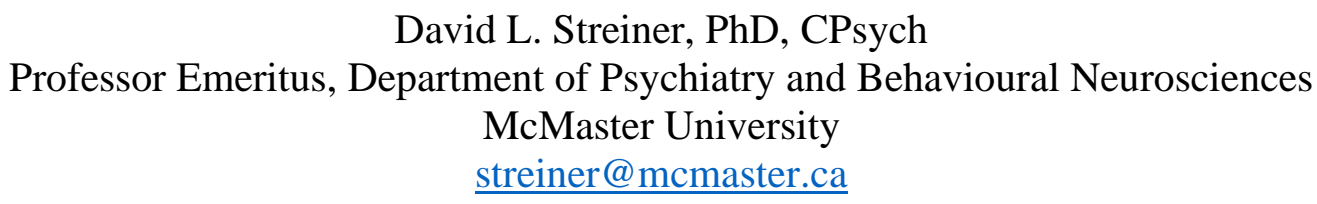

Objective: To evaluate the benefits of vaccine mandates and vaccine passports (VMVP) for SARS-CoV-2 by estimating the benefits of vaccination and exclusion of unvaccinated people from different settings.

Methods: Quantified the benefits of vaccination using meta-analyses of randomized controlled trials (RCTs), cohort studies, and transmission studies to estimate the relative risk reduction (RRR), absolute risk reduction (ARR), and number needed to vaccinate (NNV) for transmission, infection, and severe illness/hospitalization. Estimated the baseline infection risk and the baseline transmission risks for different settings. Quantified the benefits of exclusion using these data to estimate the number of unvaccinated people needed to exclude (NNE) to prevent one transmission in different settings. Modelled how the benefits of vaccination and exclusion change as a function of baseline infection risk. Studies were identified from recent systematic reviews and a search of MEDLINE, MEDLINE In-Process, Embase, Global Health, and Google Scholar.

Results: Data on infection and severe illness/hospitalization were obtained from 10 RCTs and 19 cohort studies of SARS-CoV-2 vaccines, totalling 5,575,049 vaccinated and 4,341,745 unvaccinated participants. Data from 7 transmission studies were obtained, totalling 557,020 index cases, 49,328 contacts of vaccinated index cases, and 1,294,372 contacts of unvaccinated index cases. The estimated baseline infection risk in the general population is $3.04 \%$. The estimated breakthrough infection risk in the vaccinated population is $0.57 \%$. Vaccines are very effective at reducing the risk of infection $(\mathrm{RRR}=88 \%, \mathrm{ARR}=2.59 \%, \mathrm{NNV}=39)$ and severe illness/hospitalization $(\mathrm{RRR}=89 \%, \mathrm{ARR}=0.15 \%, \mathrm{NNV}=676)$ in the general population. While the latter effect is small, vaccines nearly eliminate the baseline risk of severe illness/hospitalization (0.16\%). Among an infected person's closest contacts (primarily household members), vaccines reduce transmission risk ( $R R R=41 \%, A R R=11.04 \%, N N V=9)$. In the general population, the effect of vaccines on transmission risk is likely very small for most settings and baseline infection risks (NNVs $\geq 1,000)$. Infected vaccinated people have a nontrivial transmission risk for their closest contacts $(14.35 \%)$, but it is less than unvaccinated people $(23.91 \%)$. The transmission risk reduction gained by excluding unvaccinated people is very small for most settings: healthcare $(\mathrm{NNE}=4,699)$, work/study places $(\mathrm{NNE}=2,193)$, meals/gatherings $(\mathrm{NNE}=531)$, public places $(\mathrm{NNE}=1,731)$, daily conversation $(\mathrm{NNE}=587)$, and transportation $(\mathrm{NNE}=4,699)$. Exclusion starts showing benefits on transmission risk for some settings when the baseline infection risk is between $10 \%$ to $20 \%$. 
Conclusions: The benefits of VMVP are clear: the coercive element to these policies will likely lead to increased vaccination levels. Our study shows that higher vaccination levels will drive infections lower and almost eliminate severe illness/hospitalization from the general population. This will substantially lower the burden on healthcare systems. The benefits of exclusion are less clear. The NNEs suggest that hundreds, and even thousands, of unvaccinated people may need to be excluded from various settings to prevent one SARS-CoV-2 transmission from unvaccinated people. Therefore, consideration of the costs of exclusion is warranted, including staffing shortages from losing unvaccinated healthcare workers, unemployment/unemployability, financial hardship for unvaccinated people, and the creation of a class of citizens who are not allowed to fully participate in many areas of society.

Registration: This study is not registered.

Funding: This study received no grant from any funding agency, commercial, or not-for-profit sectors. It has also received no support of any kind from any individual or organization.

Acknowledgement: We thank numerous colleagues who provided helpful comments and criticisms during the writing of this study. We are fully vaccinated healthcare workers. 
medRxiv preprint doi: https://doi.org/10.1101/2021.11.10.21266188; this version posted November 11, 2021. The copyright holder for this preprint (which was not certified by peer review) is the author/funder, who has granted medRxiv a license to display the preprint in perpetuity.

It is made available under a CC-BY-NC-ND 4.0 International license .

\section{Introduction}

Vaccine mandates and vaccine passports (VMVP) for severe acute respiratory syndrome coronavirus 2 (SARS-CoV-2) are being implemented globally because their benefits may return societies to normality. These policies reduce risks (e.g., infection, transmission) by (1) increasing vaccination levels through coercion and (2) excluding those who remain unvaccinated from many areas (e.g., work, leisure, transportation). Increased vaccination moves populations closer to herd immunity, reducing the burden of SARS-CoV-2. Exclusion is meant to reduce the transmission risk posed by unvaccinated populations and is a key justification for VMVP. ${ }^{1}$ There are three uncertainties which make it hard to analyse the benefits of VMVP.

First, we do not know how effective VMVP will be at increasing vaccination and how many unvaccinated people need to be excluded to do so. Only controlled trials can determine this prospectively, given potential confounders driving any observed increases in vaccination. However, such trials are not feasible. Determining effectiveness retrospectively is also difficult because of confounders (e.g., differences in implementation, enforcement) and risks waiting for harm to be done before effectiveness is known. We can, however, analyse the benefits of vaccination and excluding unvaccinated people - the goal of this study - to better understand the benefits of VMVP.

Second, while vaccines clearly reduce many risks of SARS-CoV-2, the transmission data are only starting to emerge. Our study identified a growing literature on vaccines and transmission..$^{2-13}$ These studies show benefit for transmission, but only report various metrics related to the relative risk reduction (RRR). RRR is 1 minus the relative risk (RR), where RR is the ratio of case rates in the vaccinated vs. unvaccinated groups. The absolute risk reduction (ARR) is another helpful way to quantify benefit using the risk difference between unvaccinated 
vs. vaccinated groups. It is the basis for the number needed to vaccinate (NNV=1/ARR), analogous to the number needed to treat (NNT). NNV is the number needed to vaccinate to prevent one case. Baseline risks influence the ARR and NNV, such that the lower the baseline risk, the lower the ARR and the higher the NNV, and vice versa. Baseline risks for SARS-CoV-2 are the cumulative incidence of the outcome in the unvaccinated general population. They are partly a property of the disease (e.g., virulence), time at risk, setting (e.g., proximity), and individuals (e.g., age). The RRR is more constant across baseline risks because it is mainly a property of treatments. Both the RRR and ARR are useful, but the latter is necessary to contextualize treatment benefit within the baseline risk. Thus, ARRs and NNVs are needed to quantify the absolute benefits of VMVP on transmission risk.

A third uncertainty is the number of unvaccinated people we need to exclude to reduce transmission risk. This is critical to determining the benefits of exclusion. Doing so requires using baseline transmission risks to calculate a metric similar to the NNV, which we call the 'number needed to exclude' (NNE=1/ARR). The difference is that the ARR of the NNE is the baseline transmission risk. The basis for the NNE is that exclusion removes all unvaccinated people, such that the ARR is just the baseline transmission risk in the unvaccinated population. Thus, the NNE is the number of unvaccinated people who must be excluded from a setting to prevent one transmission from unvaccinated people in that setting. NNE is helpful because it quantifies how many unvaccinated people need to be excluded to reduce the transmission risk specific to unvaccinated populations. The NNE does not tell us the number of unvaccinated people who need to be excluded by VMVP as the "price" for increased vaccinations leading to reduced transmissions overall. This depends on the NNE and NNV, in addition to vaccination levels in the general population in response to VMVP. For example, if VMVP increase 
vaccination levels to $90 \%$ in a population of 1,000 unvaccinated people, 100 people will be excluded. These 100 people are the "price" society pays for the transmission risk reductions driven by increased vaccinations in response to VMVP. This number needed to "pay" (NNP) for each transmission prevented overall can be estimated using the NNE and NNV and modelling different vaccination levels in the general population (see Methods).

Critically, societies need to be mindful of baseline transmission risks because when they are low, the NNE increases exponentially (Figure 1). Figure 1 shows that the transmission risk reduction gained by excluding unvaccinated people becomes very small when baseline risks are low, especially below $0.40 \%$ to $0.30 \%$. This is the range of the ARRs of acetylsalicylic acid (ASA) in primary prevention of cardiovascular disease (CVD) outcomes (NNTs $\geq 250$ to $333) .{ }^{14-16}$

The purpose of this study was to use meta-analyses to help address these uncertainties by estimating the benefits of VMVP in terms of vaccination and exclusion. First, we estimated the benefits of SARS-CoV-2 vaccines on reducing transmission, infection, severe illness/hospitalization, and death. We did this by conducting a meta-analysis of the transmission studies and another of the randomized controlled trials (RCTs) and cohort studies of SARS-CoV2 vaccines identified in recent systematic reviews. ${ }^{17-19}$ The meta-analytic estimates of the RRR, ARR, and NNV for these outcomes allowed us to quantify the relative and absolute benefits of VMVP-driven increases in vaccination. Second, we quantified the absolute benefits of excluding unvaccinated people by calculating the NNE and NNP from our estimates of (1) the baseline infection risk in the general population and (2) the baseline transmission risks for different settings (e.g., household, healthcare, work). We also modelled how the NNE and NNP change if 
baseline infection risks increase as societies reopen. Finally, we offer indicators societies can use to determine when to relax VMVP.

\section{Methods}

\section{Selection of studies and search criteria}

We selected RCTs and cohort studies of adults identified in three recent systematic reviews. ${ }^{17-19}$ Transmission risks and their $95 \%$ confidence intervals (CIs) were extracted from a recent systematic review and meta-analysis by Zhao et al $(2021)^{20}$ of the higher-quality studies. Zhao et al reported the transmission risks for different settings: households, healthcare, work/study places, meals/gatherings, public places, daily conversation, and transportation. These studies were all pre-vaccination and thus the estimates were from unvaccinated individuals. We performed a systematic review and meta-analysis of the studies examining the effect of SARSCoV-2 vaccines on transmission. We searched MEDLINE, MEDLINE In-Process, Embase, and Global Health from the date of their inception to October 29, 2021, with no language restrictions. We used the search terms "coronavirus disease 2019", "COVID-19", "COVID”, "severe acute respiratory syndrome coronavirus 2", or "SARS-CoV-2", combined with "vaccine*”, combined with "transmission*", "secondary attack*", "SAR", "contact trac*”, or "close contact*". We identified additional reports by searching the reference lists and using Google Scholar's cited-by function of the included studies.

\section{Outcomes and extraction}

Our primary outcomes were the number of cases of transmission, infection, severe illness/hospitalization, and SARS-CoV-2-related death for vaccinated vs. unvaccinated groups and their sample sizes. Using the total sample sizes in the denominators facilitated estimation of the general population effects. Secondary outcomes were the number of cases of severe 
medRxiv preprint doi: https://doi.org/10.1101/2021.11.10.21266188; this version posted November 11, 2021. The copyright holder for this

It is made available under a CC-BY-NC-ND 4.0 International license .

illness/hospitalization and SARS-CoV-2-related death among infected persons for vaccinated vs. unvaccinated groups. The denominators were the number of infections in each group. Details are in Supplementary Table S1. Data on fully vaccinated groups was extracted whenever possible. Total sample sizes were approximated from the reports of two cohort studies, and we used the number of tests in two other cohort studies. All but two studies reported infection data. If multiple metrics of infection were reported (e.g., all vs. symptomatic vs. asymptomatic), the higher number was extracted. If multiple metrics of severe illness/hospitalization were reported, the higher number was extracted. If reported, we extracted data on the groups which were seronegative at baseline to minimize the confounding influence of natural immunity. Safety data were not extracted because this has been reviewed elsewhere ${ }^{21}$ showing that SARS-CoV-2 vaccines are safe in adults. One author (AP) performed the study selection and data extraction, which was twice checked to confirm reliability and fidelity. Raw data is freely available online: https://tinyurl.com/tvheppj4. Data were extracted from reports into standardized electronic forms. For the RCTs and cohort studies, data on vaccine, number of doses, sex, age, country, comparator, study period, and start of follow-up relative to dose were extracted. For the transmission studies, data on vaccine, number of doses, country, index case sample size, contact sample size, contact population, study period, and variant were extracted. Results are tabulated in the online supplement.

\section{Data analysis}

For each study we calculated the RR, RRR, ARR, and NNV for the primary and secondary outcomes, in addition to the baseline risk (risk of the outcome in the unvaccinated group) and breakthrough risk (risk of the outcome in the vaccinated group). For the transmission studies we calculated the transmission risks for the vaccinated vs. index cases. Analyses were 
medRxiv preprint doi: https://doi.org/10.1101/2021.11.10.21266188; this version posted November 11, 2021. The copyright holder for this preprint (which was not certified by peer review) is the author/funder, who has granted medRxiv a license to display the preprint in perpetuity.

It is made available under a CC-BY-NC-ND 4.0 International license .

conducted in $\mathrm{R}$ with the metafor package. ${ }^{22} 23 \mathrm{We}$ used random effects (restricted maximumlikelihood estimator, REML) models to combine the log RRs and ARRs. The summary estimates were converted to the RRR and NNV. This allowed us to estimate the relative and absolute benefits of vaccines on reducing transmission, infection, severe illness/hospitalization, and death in the general population and among infected persons. The $I^{2}$ statistic and its $95 \%$ CI were calculated to convey the amount of heterogeneity.

We used random effects (REML) models to estimate the baseline, breakthrough, and transmission risks. The most important were the baseline infection risk and the unvaccinated transmission risk. Note, unvaccinated transmission risks are not true baseline risks. This is because they are the risk among infected unvaccinated index cases, not the unvaccinated general population per se. Estimating baseline transmission risks requires calculating the combined probability of infection and transmission because a person must be infected first before they can transmit SARS-CoV-2. Thus, baseline transmission risks for different settings were estimated by multiplying the unvaccinated transmission risks in Zhao et al and our analysis by the baseline infection risk (3.04\%) we estimated from the RCTs and cohort studies (Supplementary Table S3). We modelled the effect of increasing baseline infection risks $(5 \%, 10 \%$, and 20\%) on baseline transmission risks to simulate different scenarios as societies reopen. $20 \%$ is a "worst case scenario" since the baseline infection risk would be in the range of the unvaccinated transmission risk $(23.91 \%)$ among an infected person's closest contacts estimated in our analysis (Supplementary Table S8).

The baseline transmission risks and the RRR of vaccines on transmission allowed us to calculate four key metrics for each setting and baseline infection risk $(3.04 \%, 5 \%, 10 \%, 20 \%)$. The first was the NNE. The second was the ARR and NNV of vaccines on transmission risk. 
ARRs were calculated by multiplying baseline transmission risks (Table 2) by the RRR we estimated from the large transmission studies in our meta-analysis $(0.41,41 \%)$ (Supplementary Table S8). Recall, the ARR is the raw difference between the risks in the unvaccinated vs. vaccinated groups and RRR is the percent difference between them (1 minus RR). Since we know the baseline transmission risks (Table 2), multiplying each risk by the RRR gives the ARR and thus the NNV. One can apply the same RRR across baseline risks to estimate the ARRs and NNVs because RRRs are fairly constant across baseline risks since they are a property of vaccines.

The third metric was the vaccinated transmission risk. These were estimated by subtracting the ARR (Table 3) from its corresponding baseline transmission risk (Table 2). The residual is the transmission risk the vaccinated population poses to others.

The fourth metric was the NNP. The NNP is calculated:

$$
N N P=\frac{U V}{\left(A R R_{V} \times V\right)+\left(A R R_{U V} \times U V\right)}=\frac{U V}{\frac{V}{N N V}+\frac{U V}{N N E}}
$$

$A R R_{V}$ is the ARR of vaccines on transmission in that setting (Supplementary Table S10) and $A R R_{U V}$ is the $\mathrm{ARR}$ of exclusion on transmission in that setting (i.e., the baseline transmission risk) (Table 2). The ARRs are weighted by the effectiveness of VMVP (i.e., vaccination levels in the general population). $V$ is the proportion of people in the general population who get vaccinated. $U V$ is the proportion of people in the general population who remain unvaccinated $(U V=1-V)$. The numerator is the total number (expressed as a proportion) of unvaccinated people at a given vaccination level. The denominator is the overall ARR of VMVP on transmission in a setting at a given vaccination level. The denominator can be expressed 
medRxiv preprint doi: https://doi.org/10.1101/2021.11.10.21266188; this version posted November 11, 2021. The copyright holder for this preprint (which was not certified by peer review) is the author/funder, who has granted medRxiv a license to display the preprint in perpetuity.

It is made available under a CC-BY-NC-ND 4.0 International license .

equivalently in terms of the NNV and NNE, which expresses the total number of transmissions prevented by VMVP in a setting at a given vaccination level.

The NNP tells us - at a given level of vaccination in the general population — how many unvaccinated people need to be excluded from a setting for every one transmission prevented overall in that setting (from exclusion and vaccination). Thus, the value of the NNP says that, for every one transmission prevented overall, $X$ number of unvaccinated people need to be excluded. The NNP is the "price" society pays for preventing one transmission overall. However, the NNP does not tell us how many unvaccinated people need to be excluded to reduce the risks specific to unvaccinated populations. The NNE quantifies this. The NNE tells us how many unvaccinated people must be excluded from a setting to prevent one transmission from unvaccinated people in that setting, regardless of the level of vaccination in the general population. If vaccination levels are $100 \%$, then the NNP equals zero because $U V$ equals zero (there are no unvaccinated people to exclude). If vaccination levels are $0 \%$, NNP reduces to the NNE because $V$ equals zero (everyone must be excluded because everyone is unvaccinated). The NNP is always less than the NNE (unless $V$ equals zero) because of the additional risk reduction gained from vaccinations.

\section{Results}

10 RCTs and 19 cohort studies of SARS-CoV-2 vaccines on infection, severe illness/hospitalization, and death were identified in the systematic reviews ${ }^{17-19}$ and included in our meta-analysis (Supplementary Table S1). Excluded reports are in Supplementary Table S2. 5,575,049 vaccinated (V) and 4,341,745 unvaccinated (UV) participants were included in our analysis of infection, which was the largest analysis (Supplementary Table S3). The vaccines included BNT162b2 (Comirnaty, BioNTech/Pfizer: $n$ effects=14, V=5,337,467, UV=4,202,165), ChAdOx1 nCoV-19 (Vaxzevria, AstraZeneca: $n$ effects=6, V=96,745, UV=813,192), 
Ad26.COV2.S (Janssen: $n$ effects=2, V=21,293, UV=37,288), mRNA-1273 (Spikevax,

Moderna: $n$ effects=2, V=17,514, UV=28,770), WIV04 (Sinopharm: $n$ effects=1, V=12,743, $\mathrm{UV}=12,737$ ), HB02 (Sinopharm: $n$ effects=1, V=12,726, UV=12,737), Gam-COVID-Vac (Sputnik V: $n$ effects $=1, \mathrm{~V}=14,964, \mathrm{UV}=4,902)$, and NVX-CoV2373 (Novavax: $n$ effects $=1$, $\mathrm{V}=1,357, \mathrm{UV}=1,327$ ). There were four reports of multiple vaccines (mainly BNT162b2 and ChAdOx1 nCoV-19) which did not report the effects separately and were analysed as a group. The sizes of the other primary and secondary outcome analyses are in Supplementary Tables S47.

7,059 citations were identified by the database search and 6 from the reference list/Google scholar cited-by function search (Supplementary Figure S1). 29 potentially eligible articles were retrieved in full-text. 7 studies of the effect of vaccines on transmission were included in our meta-analysis (Supplementary Table S8). Excluded reports are in Supplementary Table S9. This is a rapidly emerging literature since most reports were posted in August to October 2021. Across these 7 studies there were 49,328 contacts of vaccinated index cases and $1,294,372$ contacts of unvaccinated index cases. These were the closest contacts of the index cases, primarily household members. There was a total of 557,020 index cases. There were two small studies with less than 300 index cases. ${ }^{57}$ We describe the meta-analysis of the large studies to provide more robust estimates. Study periods were between December 2020 to September 2021. Studies were from the Netherlands, ${ }^{213} \mathrm{UK}^{347}{ }^{34}$ Israel, ${ }^{5}$ and Spain. ${ }^{6}$ All but one study ${ }^{4}$ reported the dominant variant: Alpha $(n=2),{ }^{25}$ Delta $(n=2),{ }^{713}$ and $\sim 50 \%$ Alpha and $\sim 50 \%$ delta $(n=2){ }^{36}$

Table 1 summarizes the meta-analysis of the baseline risks and the effect of vaccines on risk of infection, severe illness/hospitalization, and death (see Supplementary Tables S3-7 for 
details). The estimated baseline infection risk in the general population is $3.04 \%$. This is consistent with the very crude baseline infection risk $(3.15 \%)$ using the number of confirmed SARS-CoV-2 globally (248,467,363 as of 5-Nov-2021) and the global population (7.9 billion). ${ }^{24}$ The estimated breakthrough infection risk in the vaccinated population is $0.57 \%$. The estimated baseline risk of severe illness/hospitalization in the general population is $0.16 \%$. Among infected persons, it is $11.02 \%$. This indicates that SARS-CoV-2 is a disease with a high risk of morbidity for people in their middle ages or older, which was the age range of most participants in the RCTs and cohort studies (Supplementary Table S1). There were too few SARS-CoV-2-related deaths in the studies to meaningfully analyse these data.

SARS-CoV-2 vaccines are very effective at reducing the risk of infection ( $R R R=88 \%$, $\mathrm{ARR}=2.59 \%, \mathrm{NNV}=39)$ and severe illness/hospitalization $(\mathrm{RRR}=89 \%, \mathrm{ARR}=0.15 \%, \mathrm{NNV}=676)$ in the general population. While the latter effect is small, the ARR is almost the same as the baseline risk $(0.16 \%)$. This means vaccines almost eliminate the baseline risk of severe illness/hospitalization in the general population. The secondary analysis of severe illness/hospitalization among infected persons was statistically underpowered due to the small numbers of infections among the vaccinated. However, if a person is infected, vaccines partially protect against severe illness/hospitalization (ARR=5.64\%). Among an infected person's closest contacts (primarily household members), vaccines reduce transmission risk, but the RRR is smaller than for infection ( $R R R=41 \%, A R R=11.04 \%, N N V=9)$ (Supplementary Table S8). The ARR is high because the unvaccinated transmission risk is $23.91 \%$ among their closest contacts.

Supplementary Table S10 summarizes the estimated effects of SARS-CoV-2 vaccines on transmission risk among infected persons and in the general population for different settings. In the general population, the effects are very small for most settings and baseline infection risks 
medRxiv preprint doi: https://doi.org/10.1101/2021.11.10.21266188; this version posted November 11, 2021. The copyright holder for this preprint (which was not certified by peer review) is the author/funder, who has granted medRxiv a license to display the preprint in perpetuity.

It is made available under a CC-BY-NC-ND 4.0 International license .

$(\mathrm{NNVs} \geq 1,000)$. The reason is because, while vaccines reduce transmission risk $(41 \%)$, baseline transmission risks are very low to begin with. Supplementary Table S11 summarizes the transmission risks of vaccinated people in different settings. The transmission risk postvaccination among infected persons is notable for some settings: closest contacts $(14.35 \%)$, households $(7.08 \%)$, meals/gatherings (3.66\%), and daily conversation (3.30\%). This means there is a nontrivial transmission risk if a vaccinated person is infected, especially for their closest contacts.

Table 2 summarizes the estimated benefits of excluding unvaccinated people on transmission risk among infected persons and in the general population. For a baseline infection risk of $3.04 \%$, the transmission risk reduction in the general population gained by excluding unvaccinated people is very small for most settings: healthcare (NNE=4,699), work/study places (NNE=2,193), meals/gatherings ( $\mathrm{NNE}=531)$, public places $(\mathrm{NNE}=1,731)$, daily conversation $(\mathrm{NNE}=587)$, and transportation $(\mathrm{NNE}=4,699)$. These NNEs are within and some are above the NNTs of ASA for primary prevention in CVD (NNTs $\geq 250) .{ }^{14-16}$ The NNEs are similar if the baseline infection risk is 5\%. Exclusion starts showing benefits for some settings between $10 \%$ to $20 \%$ baseline infection risk: meals/gatherings $(\mathrm{NNE}=161$ to 81$)$, public places $(\mathrm{NNE}=526$ to 263), and daily conversation ( $\mathrm{NNE}=179$ to 89 ). However, the benefits of exclusion remain small for healthcare $(\mathrm{NNE}=714)$, work/study places $(\mathrm{NNE}=333)$, and transportation $(\mathrm{NNE}=714)$ even if the baseline infection risk is $20 \%$.

Figure 2 plots the NNPs for different settings, baseline infection risks, and vaccination levels. The 90-100\% ranges are shown to illustrate the effects of high levels of vaccination in the general population. For a baseline infection risk of 3.04\%, the numbers of unvaccinated people excluded for every one transmission prevented overall starts to be relatively few $(\mathrm{NNP}<250)$ in 
medRxiv preprint doi: https://doi.org/10.1101/2021.11.10.21266188; this version posted November 11, 2021. The copyright holder for this preprint (which was not certified by peer review) is the author/funder, who has granted medRxiv a license to display the preprint in perpetuity.

It is made available under a CC-BY-NC-ND 4.0 International license .

daily conversations and meals/gatherings at $\sim 75 \%$ vaccination. Public places and work/study places only reach this point at $\sim 95 \%$ vaccination, whereas healthcare and transportation start at $\sim 98 \%$ vaccination. The NNP remains over 1,000 for healthcare and transportation up until $\sim 90 \%$ vaccination. If baseline infection risks increase to $10 \%$ or $20 \%$, the NNPs decline substantially because the NNVs and NNEs decrease (Supplementary Table S10 and Table 2). This means that, when baseline infection risks are high, fewer unvaccinated people need to be excluded for every one transmission prevented overall by VMVP.

\section{Discussion}

VMVP use coercion to increase vaccination levels and exclude those who remain unvaccinated from many areas (e.g., work, leisure, transportation). Exclusion is meant to reduce the transmission risk posed by unvaccinated populations and is a key justification for VMVP. ${ }^{1}$ We ran large-scale meta-analyses of SARS-CoV-2 vaccines which included hundreds of thousands of participants to estimate the benefits of these two aspects of VMVP. We found that SARS-CoV-2 vaccines are very effective at reducing the relative and absolute risk of infection $(\mathrm{RRR}=88 \%, \mathrm{ARR}=2.59 \%, \mathrm{NNV}=39)$ and severe illness/hospitalization $(\mathrm{RRR}=89 \%$, $\mathrm{ARR}=0.15 \%, \mathrm{NNV}=676$ ) in the general population. While the latter effect is small, vaccines nearly eliminate the baseline risk of severe illness/hospitalization $(0.16 \%)$. The NNV for infection is similar to influenza and HPV vaccines. ${ }^{25} 26$ Among an infected person's closest contacts (primarily household members), vaccines reduce transmission risk, but the RRR is smaller than for infection $(\mathrm{RRR}=41 \%, \mathrm{ARR}=11.04 \%, \mathrm{NNV}=9)$.

The benefits of excluding unvaccinated people on reducing transmission risk are less clear. We estimated the baseline infection risk (3.04\%) from the analysed studies to calculate the baseline transmission risk in the general population for different settings. From these we could 
medRxiv preprint doi: https://doi.org/10.1101/2021.11.10.21266188; this version posted November 11, 2021. The copyright holder for this preprint (which was not certified by peer review) is the author/funder, who has granted medRxiv a license to display the preprint in perpetuity.

It is made available under a CC-BY-NC-ND 4.0 International license .

calculate the NNE and NNP, which quantify different aspects of the risk reductions gained from excluding unvaccinated people. We also modelled how the NNE and NNP change depending on the baseline infection risk, including a "worst case scenario" of a $20 \%$ baseline risk. The NNEs show that the benefits of exclusion are in the range (and sometimes higher) than the NNTs of ASA for primary prevention in CVD. ${ }^{14-16}$ This is notable given that ASA is not generally recommended for primary prevention in all adults because the very small benefits (NNTs $\geq 250$ to 333) do not outweigh the risk of harm. ${ }^{16}$ The estimated NNEs suggest that hundreds, and even thousands, of unvaccinated people may need to be excluded from various settings to prevent one SARS-CoV-2 transmission from unvaccinated people (Table 2). Exclusion starts showing benefits on transmission risk for some settings when the baseline infection risk is between $10 \%$ to $20 \%$.

The NNPs (Figure 2) suggest that, at a baseline infection risk of 3.04\%, vaccination levels may need to reach at least $\sim 95 \%$ to $\sim 98 \%$ before only relatively few unvaccinated people $(\mathrm{NNP}<250)$ are excluded for every one transmission prevented overall in public areas, work/study places, healthcare, and transportation. They may need to reach at least $\sim 75 \%$ before the same effects are seen in daily conversations and meals/gatherings. Until $~ 90 \%$ vaccination, more than 1,000 unvaccinated people may need to be excluded to prevent one transmission overall in healthcare and transportation settings. Since the NNPs are less than the NNEs, excluding, for instance, 1,000 unvaccinated people from healthcare settings still does not prevent one transmission from unvaccinated people since the NNE for healthcare is 4,699 (at a 3.04\% baseline infection risk). Rather, excluding these 1,000 people is the "price" society pays for the benefits of $90 \%$ vaccination, but excluding them falls short of reducing the transmission risk specific to those unvaccinated people. Finally, we found that infected vaccinated people have 
medRxiv preprint doi: https://doi.org/10.1101/2021.11.10.21266188; this version posted November 11, 2021. The copyright holder for this preprint (which was not certified by peer review) is the author/funder, who has granted medRxiv a license to display the preprint in perpetuity.

It is made available under a CC-BY-NC-ND 4.0 International license .

nontrivial transmission risks for their closest contacts (14.35\%). This is consistent with emerging epidemiological data showing no correlation between the level of full vaccination and the incidence of new SARS-CoV-2 infections. ${ }^{27}$

The benefits of VMVP are clear: the coercive element to these policies will likely lead to increased vaccination levels. Our study shows that higher vaccination levels will drive infections lower and almost eliminate severe illness/hospitalization from the general population. This will substantially lower the burden on healthcare systems. It also explains why unvaccinated patients now constitute most SARS-CoV-2 hospitalizations and intensive care unit (ICU) admissions. ${ }^{28}$ Among infected persons, vaccines reduce the risk of transmission to their closest contacts by about $41 \%$. However, in the general population, the magnitude of this effect is likely very small (in the range of ASA in primary prevention of CVD).

These benefits come with costs. An unknown percentage of people will not get vaccinated despite VMVP. This means those unvaccinated people will be excluded from many areas of modern life (e.g., many places of work, leisure, transportation, education), especially work in healthcare settings. The NNEs and NNPs show that the transmission risk reduction gained by excluding unvaccinated people is very small for most settings (especially healthcare and transportation settings). In light of this, there are at least three costs to consider. The first is healthcare-specific. There is a possibility of staffing shortages from the loss of unvaccinated workers, which may have downstream effects on patient care. This may be limited by increases in vaccinations in response to VMVP. Second, there is the cost of unemployment and - in some cases - unemployability if vaccines are a condition of employment or higher-education in most organizations. This would mean unvaccinated individuals and their families will face financial hardship. This may have downstream effects on their mental/physical health. A third cost of 
medRxiv preprint doi: https://doi.org/10.1101/2021.11.10.21266188; this version posted November 11, 2021. The copyright holder for this

It is made available under a CC-BY-NC-ND 4.0 International license .

exclusion is the creation of a class of citizens who are not allowed to fully participate in many areas of society.

Baseline infection risk is critically important to evaluating the costs vs. benefits of excluding unvaccinated people. Therefore, we suggest that baseline infection risk be included as a key indicator for when to relax VMVP. It compliments other indicators, such as hospital/ICU occupancy and the basic and effective reproduction number. As societies reopen, the baseline infection risk may increase. However, it is also possible that the baseline infection risk will not increase dramatically due to high levels of vaccination and natural immunity which likely already exist in many societies. If baseline infection risks remain or decline below 3.04\% (3,040 cases per 100,000) over a 1-to-3 month period (the typical follow-up period of the studies in our meta-analysis), then consideration of whether the costs of exclusion outweigh the benefits is warranted.

Our study has some limitations. Our estimates derive from studies during a period of the pandemic when physical distancing, lockdowns, and universal masking were in place, which contained infection rates. We have tried to address this by modelling how the NNE and NNP change with increased baseline infections. We were unable to answer how much VMVP will increase vaccination levels, which requires controlled trials and cohort studies. There were too few transmission studies to perform a meta-regression/subgroup analysis or examine the moderating effects of variants and vaccines. Not all SARS-CoV-2 vaccines were included in our meta-analysis and BNT162b2 and ChAdOx1 nCoV-19 were by far the most studied. Our conclusions do not generalize to child/adolescent populations. We were unable to analyse the impact of natural immunity on reducing transmission risk. In addition to more studies of vaccines on transmission, future research should focus on health economic analyses of the costs 
vs. benefits of exclusion, natural immunity and transmission, the impact of variants, and quantifying what is an acceptable baseline risk of infection and transmission in terms of health and economic outcomes.

Notwithstanding these limitations, our study has strengths. Our estimates of the effect of SARS-CoV-2 vaccines on transmission, infection, and severe illness/hospitalization in the general population are robust because they are based on hundreds of thousands of participants. Using a recent meta-analysis ${ }^{20}$ also provided data for robust estimates of the baseline transmission risks used to calculate the NNEs and NNPs for different settings. We performed the first meta-analysis of the studies of vaccines on transmission, a rapidly emerging literature. Our study is also the first to quantify the benefits of exclusion on transmission risk. We hope that these results will assist societies and policymakers in their cost vs. benefit analyses of VMVP. 
Contributions: AP and DS conceptualized the study, wrote/edited the manuscript, and had full access to the data. AP performed the study selection, data extraction, and data analysis. AP and DS conceptualized and developed the estimation and modelling procedures. AP is the corresponding author. All authors approved the final version of the manuscript. AP is the guarantor and attests that all listed authors meet authorship criteria and that no others meeting the criteria have been omitted.

AP affirms that this manuscript is an honest, accurate, and transparent account of the study being reported, that no important aspects of the study have been omitted, and that any discrepancies from the study as planned have been explained.

Completing Interests: All authors have completed the ICMJE uniform disclosure form at http://www.icmje.org/disclosure-of-interest/ and declare: no support from any organisation for the submitted work; no financial relationships with any organisations that might have an interest in the submitted work in the previous three years; no other relationships or activities that could appear to have influenced the submitted work.

Funding: This study received no specific grant from any funding agency, commercial or not-forprofit sectors. It has also received no support of any kind from any individual or organization.

Ethical approval: Not required.

Data sharing: Raw data is freely available online: https://tinyurl.com/tvheppj4. 
medRxiv preprint doi: https://doi.org/10.1101/2021.11.10.21266188; this version posted November 11, 2021. The copyright holder for this preprint (which was not certified by peer review) is the author/funder, who has granted medRxiv a license to display the preprint in perpetuity.

It is made available under a CC-BY-NC-ND 4.0 International license .

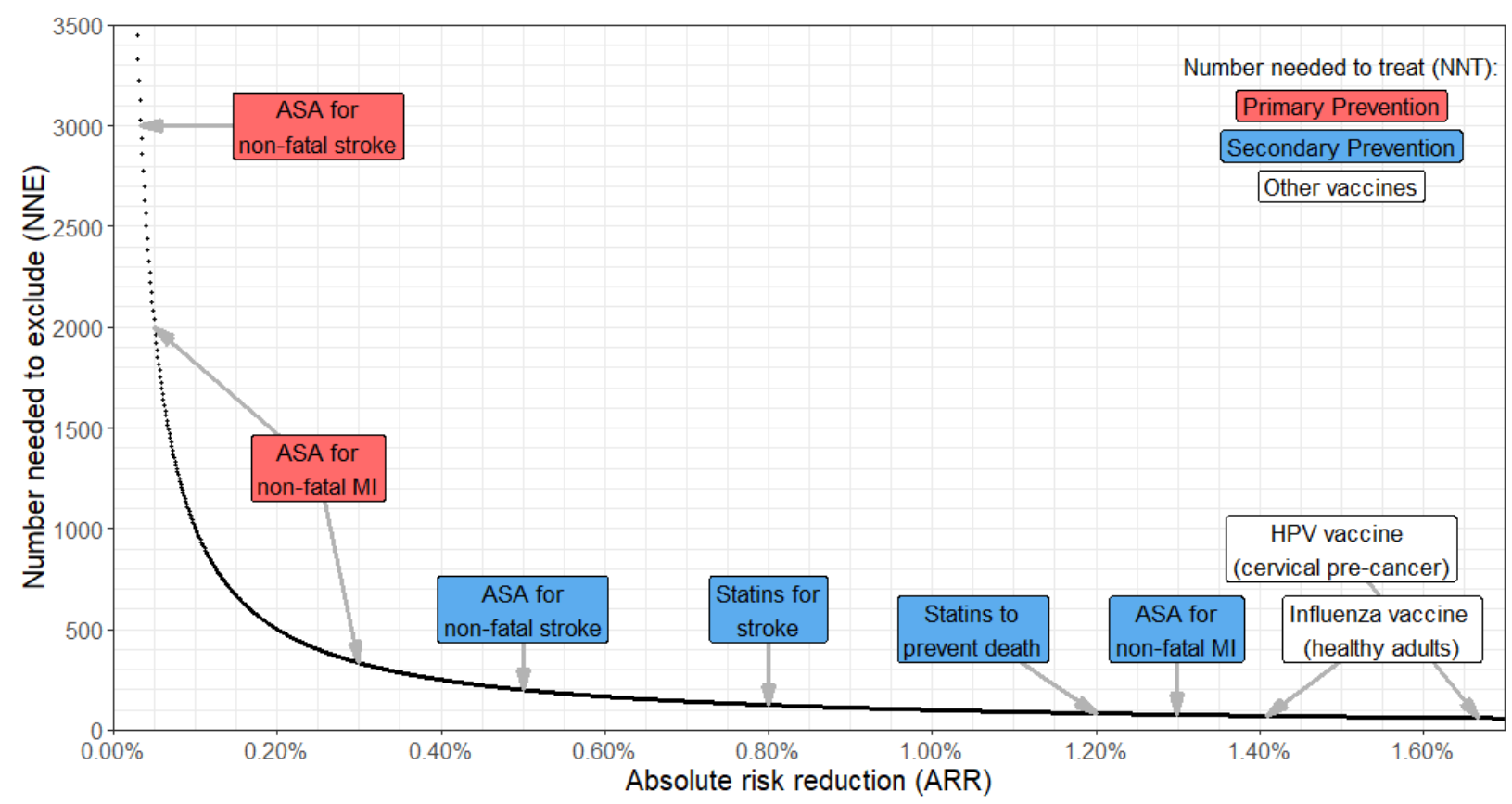

Figure 1. Relationship between baseline transmission risk and the number needed to exclude (NNE). The number needed to treat (NNT) has the same scale as the NNE (NNT=1/ARR). The only difference is that the ARR of the NNE is the baseline transmission risk. This figure shows that the risk reduction gained by excluding unvaccinated people becomes very small when baseline risks are low, especially when they are below $0.40 \%$ to $0.30 \%$. This is the range of the ARRs of acetylsalicylic acid (ASA) in primary prevention of cardiovascular disease outcomes. ${ }^{14-16}$ The NNTs of other interventions are shown for comparison. ${ }^{14} 25$ $262930 \mathrm{ARR}=$ absolute risk reduction. $\mathrm{MI}=$ myocardial infarction. $\mathrm{HPV}=$ human papillomaviruses. 
Table 1. Meta-analysis of SARS-CoV-2 vaccines on infection, severe illness/hospitalization, and death

\begin{tabular}{|c|c|c|c|c|}
\hline \multirow[b]{2}{*}{ Outcome } & \multirow[b]{2}{*}{$\begin{array}{c}\text { Baseline risk } \dagger \\
(95 \% \text { CI })\end{array}$} & \multicolumn{3}{|c|}{ Effect of vaccination $t$} \\
\hline & & $\begin{array}{c}\text { RRR } \\
(95 \% \mathrm{CI})\end{array}$ & $\begin{array}{c}\text { ARR } \\
(95 \% \mathrm{CI})\end{array}$ & $\begin{array}{c}\text { NNV } \\
(95 \% \text { CI })\end{array}$ \\
\hline \multicolumn{5}{|l|}{ General population } \\
\hline Infection & $\begin{array}{c}3.04 \% \\
(2.08 \%, 4.01 \%)\end{array}$ & $\begin{array}{c}88 \% \\
(83 \%, 92 \%)\end{array}$ & $\begin{array}{c}2.59 \% \\
(1.75 \%, 3.43 \%)\end{array}$ & $\begin{array}{c}39 \\
(29,57)\end{array}$ \\
\hline Severe illness/hospitalization & $\begin{array}{c}0.16 \% \\
(0.09 \%, 0.23 \%)\end{array}$ & $\begin{array}{c}89 \% \\
(82 \%, 93 \%)\end{array}$ & $\begin{array}{c}0.15 \% \\
(0.09 \%, 0.20 \%)\end{array}$ & $\begin{array}{c}676 \\
(489,1,094)\end{array}$ \\
\hline Death & Insufficient data & Insufficient data & Insufficient data & Insufficient data \\
\hline \multicolumn{5}{|l|}{ Among infected persons } \\
\hline \multirow[t]{2}{*}{ Severe illness/hospitalization $\S$} & $\begin{array}{c}11.02 \% \\
(6.31 \%, 15.72 \%)\end{array}$ & $\begin{array}{c}7 \% \\
(-55 \%, 44 \%)\end{array}$ & $\begin{array}{c}5.64 \% \\
(0.69 \%, 10.59 \%)\end{array}$ & $\begin{array}{c}18 \\
(9,146)\end{array}$ \\
\hline & Insufficient data & Insufficient data & Insufficient data & Insufficient data \\
\hline \multicolumn{5}{|c|}{$\begin{array}{l}\text { RRR=relative risk reduction }(1-\text { relative risk). ARR=absolute risk reduction. NNV=number needed to vaccinate. } 95 \% \mathrm{CI}=95 \% \\
\text { confidence interval. Brackets are the } 95 \% \text { confidence intervals (lower limit, upper limit). } \\
\$ \text { See Tables S3-7 for details. } \\
\dagger \text { Baseline risk is defined as the risk of the SARS-CoV-2 outcome (e.g., infection, severe illness/hospitalization, death) in the } \\
\text { unvaccinated population. } \\
\S \text { Statistically underpowered due to the small numbers of infections in the vaccinated groups for most studies. The RRR, ARR, and } \\
\text { NNV are not precise estimates. }\end{array}$} \\
\hline
\end{tabular}


Table 2. Estimated effects of excluding unvaccinated people on transmission risk among infected persons and in the general population

Baseline infection risk in the general population?

\begin{tabular}{|c|c|c|c|c|c|c|c|c|c|c|}
\hline \multirow[b]{2}{*}{ Setting } & \multicolumn{2}{|c|}{ Among infected persons } & \multicolumn{2}{|c|}{$3.04 \% \div$} & \multicolumn{2}{|c|}{$5 \%$} & \multicolumn{2}{|c|}{$10 \%$} & \multicolumn{2}{|c|}{$20 \%$} \\
\hline & $\begin{array}{c}\text { Unvacc. } \\
\text { Transm. } \\
\text { risk§ } \\
(95 \% \mathrm{CI})\end{array}$ & $\begin{array}{c}\text { NNE } \\
(95 \% \mathrm{CI})\end{array}$ & $\begin{array}{c}\text { Baseline } \\
\text { transm. } \\
\text { risk } \dagger \\
(95 \% \mathrm{CI})\end{array}$ & $\begin{array}{c}\text { NNE } \\
(95 \% \text { CI })\end{array}$ & $\begin{array}{c}\text { Baseline } \\
\text { transm. } \\
\text { risk } \dagger \\
(95 \% \mathrm{CI})\end{array}$ & $\begin{array}{c}\text { NNE } \\
(95 \% \text { CI })\end{array}$ & $\begin{array}{c}\text { Baseline } \\
\text { transm. } \\
\text { risk } \dagger \\
(95 \% \mathrm{CI})\end{array}$ & $\begin{array}{c}\text { NNE } \\
(95 \% \text { CI })\end{array}$ & $\begin{array}{c}\text { Baseline } \\
\text { transm. } \\
\text { risk } \dagger \\
(95 \% \mathrm{CI})\end{array}$ & $\begin{array}{c}\text { NNE } \\
(95 \% \text { CI })\end{array}$ \\
\hline Closest contacts & $\begin{array}{l}23.91 \% * \\
(12.00 \% \\
35.83 \%)\end{array}$ & $\begin{array}{c}4 * \\
(3,8)\end{array}$ & $\begin{array}{c}0.7269 \% \\
(0.3648 \%, \\
1.0892 \%)\end{array}$ & $\begin{array}{c}138 \\
(92,274)\end{array}$ & $\begin{array}{l}1.1955 \% \\
(0.600 \%, \\
1.7915 \%)\end{array}$ & $\begin{array}{c}84 \\
(56,167)\end{array}$ & $\begin{array}{r}2.391 \% \\
(1.200 \% \\
3.583 \%) \\
\end{array}$ & $\begin{array}{c}42 \\
(28,83)\end{array}$ & $\begin{array}{c}4.782 \% \\
(2.400 \% \text {, } \\
7.166 \%) \\
\end{array}$ & $\begin{array}{c}21 \\
(14,42)\end{array}$ \\
\hline Household $\downarrow$ & $\begin{array}{l}12.00 \% \\
(9.80 \%, \\
14.20 \%)\end{array}$ & $\begin{array}{c}8 \\
(7,10)\end{array}$ & $\begin{array}{c}0.3648 \% \\
(0.2979 \% \text {, } \\
0.4317 \%)\end{array}$ & $\begin{array}{c}274 \\
(232,336)\end{array}$ & $\begin{array}{c}0.600 \% \\
(0.490 \% \\
0.710 \%)\end{array}$ & $\begin{array}{c}167 \\
(141,204)\end{array}$ & $\begin{array}{c}1.200 \% \\
(0.980 \% \\
1.420 \%)\end{array}$ & $\begin{array}{c}83 \\
(70,102)\end{array}$ & $\begin{array}{c}2.400 \% \\
(1.960 \% \\
2.840 \%)\end{array}$ & $\begin{array}{c}42 \\
(35,51)\end{array}$ \\
\hline Healthcare $!$ & $\begin{array}{c}0.70 \% \\
(0.40 \% \\
1.10 \%) \\
\end{array}$ & $\begin{array}{c}143 \\
(91,250)\end{array}$ & $\begin{array}{c}0.0213 \% \\
(0.0122 \%, \\
0.0334 \%) \\
\end{array}$ & $\begin{array}{c}4,699 \\
(2,990,8,224)\end{array}$ & $\begin{array}{c}0.035 \% \\
(0.020 \% \\
0.055 \%) \\
\end{array}$ & $\begin{array}{c}2,857 \\
(1,818,5,000)\end{array}$ & $\begin{array}{c}0.070 \% \\
(0.040 \% \\
0.110 \%) \\
\end{array}$ & $\begin{array}{c}1,429 \\
(909,2,500)\end{array}$ & $\begin{array}{c}0.140 \% \\
(0.080 \% \\
0.220 \%) \\
\end{array}$ & $\begin{array}{c}714 \\
(455,1,250)\end{array}$ \\
\hline Work or study places! & $\begin{array}{c}1.50 \% \\
(0.80 \% \\
2.30 \%) \\
\end{array}$ & $\begin{array}{c}67 \\
(43,125)\end{array}$ & $\begin{array}{c}0.0456 \% \\
(0.0243 \%, \\
0.0699 \%)\end{array}$ & $\begin{array}{c}2,193 \\
(1,430,4,112)\end{array}$ & $\begin{array}{c}0.075 \% \\
(0.040 \% \\
0.115 \%)\end{array}$ & $\begin{array}{c}1,333 \\
(870,2,500)\end{array}$ & $\begin{array}{c}0.150 \% \\
(0.080 \% \\
0.230 \%)\end{array}$ & $\begin{array}{c}667 \\
(435,1,250)\end{array}$ & $\begin{array}{c}0.300 \% \\
(0.160 \% \\
0.460 \%)\end{array}$ & $\begin{array}{c}333 \\
(217,625)\end{array}$ \\
\hline Meal or gathering! & $\begin{array}{r}6.20 \% \\
(4.60 \% \\
7.90 \%) \\
\end{array}$ & $\begin{array}{c}16 \\
(13,22)\end{array}$ & $\begin{array}{c}0.1885 \% \\
(0.1398 \% \text {, } \\
0.2402 \%) \\
\end{array}$ & $\begin{array}{c}531 \\
(416,715)\end{array}$ & $\begin{array}{c}0.310 \% \\
(0.230 \% \\
0.395 \%) \\
\end{array}$ & $\begin{array}{c}323 \\
(253,435)\end{array}$ & $\begin{array}{c}0.620 \% \\
(0.460 \% \\
0.790 \%) \\
\end{array}$ & $\begin{array}{c}161 \\
(127,217)\end{array}$ & $\begin{array}{c}1.240 \% \\
(0.920 \%, \\
1.580 \%) \\
\end{array}$ & $\begin{array}{c}81 \\
(63,109)\end{array}$ \\
\hline Public places $\frac{!}{t}$ & $\begin{array}{c}1.90 \% \\
(1.10 \% \\
2.60 \%) \\
\end{array}$ & $\begin{array}{c}53 \\
(38,91)\end{array}$ & $\begin{array}{c}0.0578 \% \\
(0.0334 \%, \\
0.0790 \%)\end{array}$ & $\begin{array}{c}1,731 \\
(1,265,2,990)\end{array}$ & $\begin{array}{c}0.095 \% \\
(0.055 \% \\
0.130 \%)\end{array}$ & $\begin{array}{c}1,053 \\
(769,1,818)\end{array}$ & $\begin{array}{c}0.190 \% \\
(0.110 \% \\
0.260 \%) \\
\end{array}$ & $\begin{array}{c}526 \\
(385,909)\end{array}$ & $\begin{array}{c}0.380 \% \\
(0.220 \% \\
0.520 \%) \\
\end{array}$ & $\begin{array}{c}263 \\
(192,455)\end{array}$ \\
\hline Daily conversation + & $\begin{array}{c}5.60 \% \\
(0.00 \%, \\
11.30 \%)\end{array}$ & $\begin{array}{c}18 \\
(9, \text { Inf })\end{array}$ & $\begin{array}{c}0.1702 \% \\
(0.0000 \%, \\
0.3435 \%)\end{array}$ & $\begin{array}{c}587 \\
(291, \text { Inf })\end{array}$ & $\begin{array}{c}0.280 \% \\
(0.000 \% \\
0.565 \%)\end{array}$ & $\begin{array}{c}357 \\
(177, \text { Inf })\end{array}$ & $\begin{array}{c}0.560 \% \\
(0.000 \% \\
1.130 \%)\end{array}$ & $\begin{array}{c}179 \\
(88, \text { Inf })\end{array}$ & $\begin{array}{c}1.120 \% \\
(0.000 \% \\
2.260 \%)\end{array}$ & $\begin{array}{c}89 \\
(44, \text { Inf })\end{array}$ \\
\hline Transportation $\downarrow$ & $\begin{array}{c}0.70 \% \\
(0.30 \% \\
1.20 \%) \\
\end{array}$ & $\begin{array}{c}143 \\
(83,333)\end{array}$ & $\begin{array}{c}0.0213 \% \\
(0.0091 \% \text {, } \\
0.0365 \%)\end{array}$ & $\begin{array}{c}4,699 \\
(2,741,10,965)\end{array}$ & $\begin{array}{c}0.035 \% \\
(0.015 \% \\
0.060 \%)\end{array}$ & $\begin{array}{c}2,857 \\
(1,667,6,667)\end{array}$ & $\begin{array}{c}0.070 \% \\
(0.030 \% \\
0.120 \%)\end{array}$ & $\begin{array}{c}1,429 \\
(833,3,333)\end{array}$ & $\begin{array}{c}0.140 \% \\
(0.060 \% \\
0.240 \%)\end{array}$ & $\begin{array}{c}714 \\
(417,1,667)\end{array}$ \\
\hline
\end{tabular}

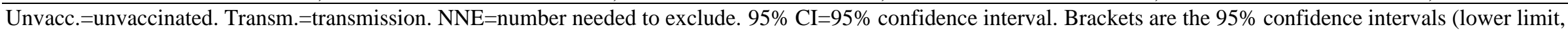
upper limit).

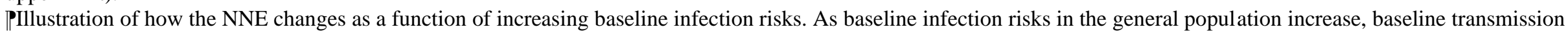
risks increase, which lowers the NNE.

†Baseline infection risk in the general population estimated from the meta-analysis (Table 1).

*The unvaccinated transmission risk here is the meta-analytic weighted average of the transmission risk in the unvaccinated groups of the large studies (Table S8).

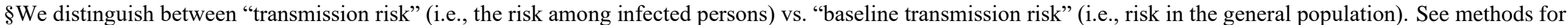
details. 
$\dagger$ Baseline transmission risks were estimated by multiplying the setting’s transmission risk by the baseline infection risk $(3.04 \%, 5 \%, 10 \%, 20 \%)$.

These transmission risks and their $95 \%$ CIs were taken from Zhao et al's $(2021)^{20}$ meta-analysis of the higher-quality transmission studies they identified. 

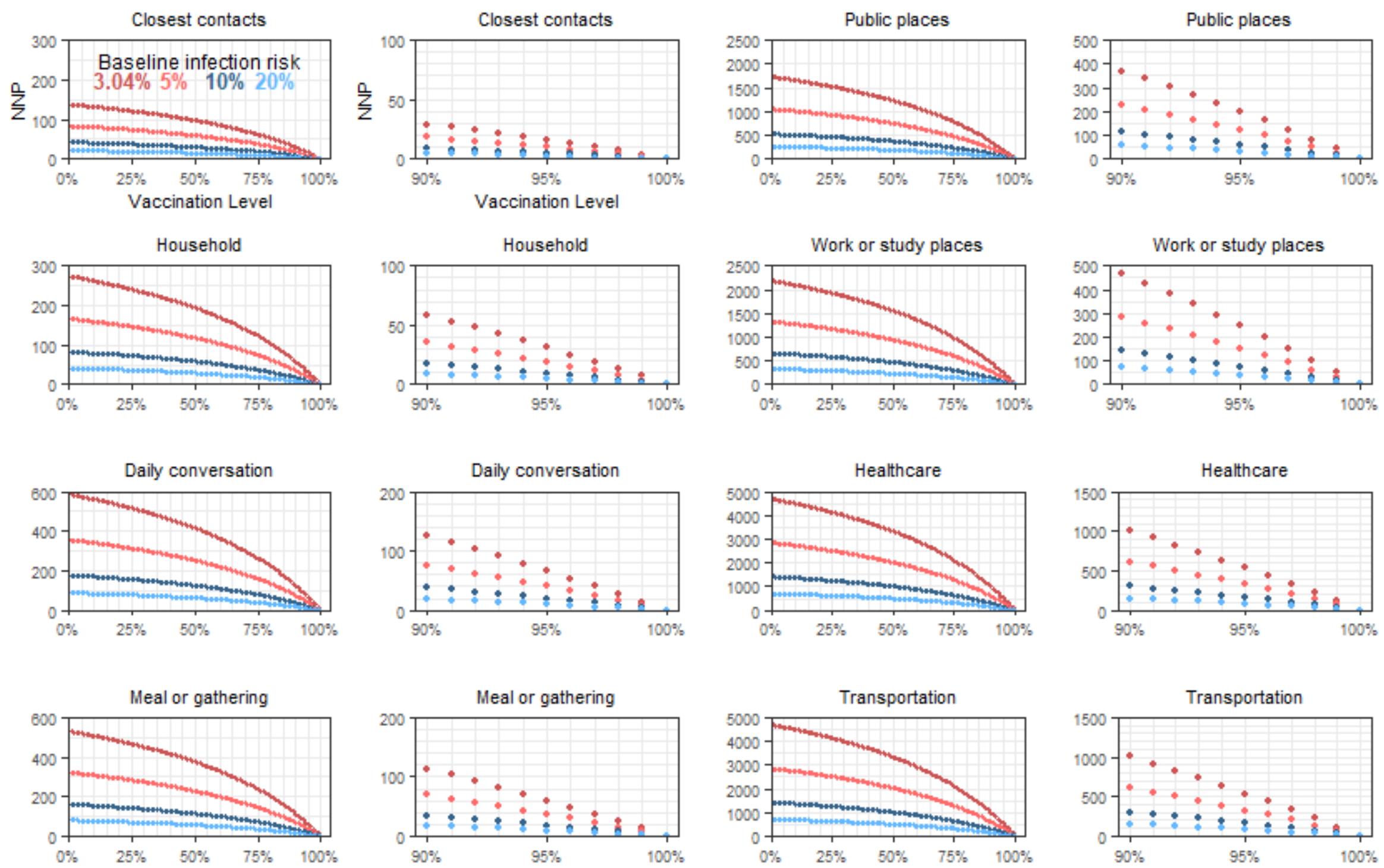

Figure 2. Modelling the number needed to pay (NNP) in terms of excluding unvaccinated people to prevent one transmission overall in different settings as a function of baseline infection risk and vaccination levels in the general population. 


\section{References}

1. Flood CM, Thomas B, Wilson K. Mandatory vaccination for health care workers: an analysis of law and policy. CMAJ 2021;193(6):E217-E20.

2. de Gier B, Andeweg S, Joosten R, et al. Vaccine effectiveness against SARS-CoV-2 transmission and infections among household and other close contacts of confirmed cases, the Netherlands, February to May 2021. Eurosurveillance 2021 Aug 5;26(31):2100640.

3. Eyre DW, Taylor D, Purver M, et al. The impact of SARS-CoV-2 vaccination on Alpha \& Delta variant transmission. medRxiv 2021 Oct 15;Available from: https://www.medrxiv.org/content/10.1101/2021.09.28.21264260v2 doi: https://doi.org/10.1101/2021.09.28.21264260

4. Harris RJ, Hall JA, Zaidi A, et al. Effect of Vaccination on Household Transmission of SARSCoV-2 in England. N Engl J Med 2021 Aug 19;385(8):759-60. doi: 10.1056/NEJMc2107717

5. Layan M, Gilboa M, Gonen T, et al. Impact of BNT162b2 vaccination and isolation on SARSCoV-2 transmission in Israeli households: an observational study. MedRxiv 2021 July 16;Available from: https://www.medrxiv.org/content/10.1101/2021.07.12.21260377v1

6. Martínez-Baz I, Trobajo-Sanmartín C, Miqueleiz A, et al. Product-specific COVID-19 vaccine effectiveness against secondary infection in close contacts, Navarre, Spain, April to August 2021. Eurosurveillance 2021 Sept 30;26(39):2100894.

7. Singanayagam A, Hakki S, Dunning J, et al. Community transmission and viral load kinetics of the SARS-CoV-2 delta (B.1.617.2) variant in vaccinated and unvaccinated individuals in the UK: a prospective, longitudinal, cohort study. The Lancet Infectious Diseases 2021;Published online October 28, 2021 doi: 10.1016/S1473-3099(21)00648-4

8. Braeye T, Cornelissen L, Catteau L, et al. Vaccine effectiveness against infection and onwards transmission of COVID-19: Analysis of Belgian contact tracing data, January-June 2021. Vaccine 2021;39(39):5456-60.

9. Prunas O, Warren JL, Crawford FW, et al. Vaccination with BNT162b2 reduces transmission of SARS-CoV-2 to household contacts in Israel. MedRxiv 2021 July 16;Available from: https://www.medrxiv.org/content/10.1101/2021.07.13.21260393v1

10. Salo J, Hagg M, Kortelainen M, et al. The indirect effect of mRNA-based Covid-19 vaccination on unvaccinated household members. MedRxiv 2021 July 7;Available from: https://www.medrxiv.org/content/10.1101/2021.05.27.21257896v1

11. Shah ASV, Gribben C, Bishop J, et al. Effect of Vaccination on Transmission of SARS-CoV2. N Engl J Med 2021 Sept 8 doi: 10.1056/NEJMc2106757

12. Siddle KJ, Krasilnikova LA, Moreno GK, et al. Evidence of transmission from fully vaccinated individuals in a large outbreak of the SARS-CoV-2 Delta variant in Provincetown, Massachusetts. medRxiv : the preprint server for health sciences 2021 doi: https://dx.doi.org/10.1101/2021.10.20.21265137

13. de Gier B, Andeweg S, Backer JA, et al. Vaccine effectiveness against SARS-CoV-2 transmission to household contacts during dominance of Delta variant (B.1.617.2), August-September 2021, the Netherlands. medRxiv 2021 Oct 14;Available from: https://www.medrxiv.org/content/10.1101/2021.10.14.21264959v1:2021.10.14.21264959 . doi: $10.1101 / 2021.10 .14 .21264959$ 
medRxiv preprint doi: https://doi.org/10.1101/2021.11.10.21266188; this version posted November 11, 2021. The copyright holder for this preprint (which was not certified by peer review) is the author/funder, who has granted medRxiv a license to display the preprint in perpetuity.

It is made available under a CC-BY-NC-ND 4.0 International license .

14. Newman D. Aspirin to Prevent a First Heart Attack or Stroke 2015 [Available from: https://www.thennt.com/nnt/aspirin-to-prevent-a-first-heart-attack-or-stroke-2/ accessed 15-Oct-2021.

15. Roach K, Ritchie M, Zehtabchi S. Aspirin For Preventing A First Heart Attack Or Stroke 2019 [Available from: https://www.thennt.com/nnt/aspirin-preventing-first-heart-attackstroke/ accessed 15-Oct-2021.

16. Angiolillo DJ, Capodanno D. Aspirin for primary prevention of cardiovascular disease in the 21st century: a review of the evidence. The American Journal of Cardiology 2021;144:S15-S22.

17. Ghazy RM, Ashmawy R, Hamdy NA, et al. Efficacy and Effectiveness of SARS-CoV-2 vaccine: A systematic review and a meta-analysis (https://www.researchsquare.com/article/rs-936074/v1). Research Square 2021 Sept 28;Preprint

18. Fan Y, Chan K-H, Hung IF-N. Safety and Efficacy of COVID-19 Vaccines: A Systematic Review and Meta-Analysis of Different Vaccines at Phase 3. Vaccines 2021;9(9):989.

19. Harder T, Koch J, Vygen-Bonnet S, et al. Efficacy and effectiveness of COVID-19 vaccines against SARS-CoV-2 infection: interim results of a living systematic review, 1 January to 14 May 2021. Eurosurveillance 2021;26(28) doi: http://dx.doi.org/10.2807/15607917.ES.2021.26.28.2100563

20. Zhao X-Y, Shen Z-Q, Sun L-T, et al. A network meta-analysis of secondary attack rates of COVID-19 in different contact environments. Epidemiol Infect:1-17.

21. Chen M, Yuan Y, Zhou Y, et al. Safety of SARS-CoV-2 vaccines: A systematic review and meta-analysis of randomized controlled trials. Infectious diseases of poverty 2021;10(1):1-12.

22. metafor: Meta-Analysis Package for R [program], 2021.

23. R: A Language and Environment for Statistical Computing [program]. Vienna, Austria: R Foundation for Statistical Computing, 2020.

24. WHO. WHO Coronavirus (COVID-19) Dashboard: World Health Organization; 2021 [Available from: https://covid19.who.int/ accessed 6-Nov-2021.

25. Li JJ, Stetz J. HPV vaccines for prevention of cervical pre-cancer in adolescent girls and women theNNT.com2018 [Available from: https://www.thennt.com/nnt/hpv-vaccinesprevention-cervical-pre-cancer-adolescent-girls-women/ accessed 15-Oct-2021.

26. Liang S. Vaccines for Preventing Influenza in Healthy Individuals 2018 [Available from: https://www.thennt.com/nnt/vaccines-preventing-influenza-healthy-individuals/ accessed 15-Oct-2021.

27. Subramanian S, Kumar A. Increases in COVID-19 are unrelated to levels of vaccination across 68 countries and 2947 counties in the United States. Eur J Epidemiol 2021:1-4.

28. Update on COVID-19 Projections: Science Advisory and Modelling Consensus Tables, COVID-19 Advisory for Ontario; 2021 Sept 28 [Available from: https://covid19sciencetable.ca/wp-content/uploads/2021/09/Update-on-COVID-19Projections_2021.09.28_English-2.pdf accessed 7-Nov-2021.

29. Newman D. Statins for Heart Disease Prevention (With Known Heart Disease) 2013 [Available from: https://www.thennt.com/nnt/statins-for-heart-disease-prevention-withknown-heart-disease/ accessed 15-Oct-2021. 
medRxiv preprint doi: https://doi.org/10.1101/2021.11.10.21266188; this version posted November 11, 2021. The copyright holder for this preprint (which was not certified by peer review) is the author/funder, who has granted medRxiv a license to display the preprint in perpetuity.

It is made available under a CC-BY-NC-ND 4.0 International license .

30. Newman D. Aspirin for Cardiovascular Prevention (After Prior Heart Attack or Stroke) 2011

[Available from: https://www.thennt.com/nnt/aspirin-for-cardiovascular-prevention-afterprior-heart-attack-or-stroke/ accessed 15-Oct-2021. 